
\title{
Zigadenus Poisoning Treated with Atropine and Dopamine
}

\author{
Patrick West, MD, B. Zane Horowitz, MD
}

Oregon Health and Science University, Oregon Poison Center, Portland, OR

\begin{abstract}
Introduction: Zigadenus (commonly known as "death camas" or "mountain camas") is a common plant in the lilly family found throughout the United States. Its onion-like roots can be mistaken for an edible plant. Ingestion may cause hemodynamic instability which has successfully been treated with atropine. It has been suggested that vasopressors may be an effective therapy for this ingestion. We report the successful use of dopamine as therapy in Zigadenus ingestion.

Case Report: A 45 year-old, previously healthy male presented to the ED with complaints of severe nausea and vomiting after ingesting two "wild onion" bulbs. He was noted to have marked hypotension and bradycardia in the ED, which initially responded to treatment with IV fluids and atropine. The plant was identified as a species of Zigadenus. After a second drop in heart rate and blood pressure in the ICU, hypotension and bradycardia were treated successfully with a dopamine infusion.

Discussion: Zigadenus ingestion presents with vomiting, hypotension and bradycardia. The hemodynamic instability responded well to atropine for 1-2 hours. Dopamine infusion was used to stabilize both heart rate and blood pressure. With supportive care, poisoned individuals become relatively asymptomatic within 24 hours of their ingestion. Patients may be discharged once asymptomatic, typically the day after ingestion, and do not have any known long term sequelae.

Conclusion: Zigadenus poisoning causes vomiting, hypotension and bradycardia. The hemodynamic instability may be treated with atropine administration and dopamine infusion.

\section{INTRODUCTION}

Zigadenus (common names "death camas "or "mountain camas") is a genus of common US plants whose bulb-like roots can easily be mistaken for other edible plants. The typical toxicity of Zigadenus involves vomiting, hypotension, and bradycardia. Treatment in the past has varied, the most prominent being atropine, with reports of success using this therapy [1,2]. There has been discussion of using vasopressors for hemodynamic instability, but no clinical reports of their use [1]. We report a case of Zigadenus ingestion with characteristic clinical course and therapeutic use of both atropine and dopamine with good results.
\end{abstract}

\section{CASE REPORT}

A 45-year-old male without significant medical history presented to the emergency department (ED) complaining of nausea, vomiting, and abdominal pain. He also complained of tingling in his fingers, headache, profuse diaphoresis, and salivation. The patient stated he had been in a high desert area near Bend, Oregon and ate the white, golf-ball-sized bulbs of two "wild onions." Two hours after his ingestion, he began to feel lightheaded, diaphoretic, and had profuse vomiting followed by onset of dull epigastric pain. He hiked out of the area, and presented to the ED 6 hours after ingestion.

On arrival, he had bilious vomiting, and appeared to be in severe distress. His initial vital signs were: temperature, 35.5C; heart rate (HR), 49 beats per minute (bpm); blood pressure (BP), 60/27 mmHg; respiratory rate 10/min; and pulse oximetry $98 \%$ on room

Keywords: Zigadenus, death camas, bradycardia, hypotension, plant, emesis

Notes: There was no outside funding of any kind used for this study.

The authors have no potential financial conflicts of interest to report.

Corresponding author: Patrick West, 3181 SW Sam Jackson Park Road, CB 550, Portland, OR 97239.Email: westp@ohsu.edu 
air. His cardiac exam was notable for regular bradycardia and poor peripheral pulses. He had unremarkable lung and abdominal exams. Neurologically he had reactive 2 -mm-wide pupils, with normal cranial nerve, motor, sensory, and cerebellar exams. His laboratory evaluation-which included CBC, UA, urine drug screen, INR, troponin, and serum ethanol-were unremarkable, except for an elevated creatinine of $1.5 \mathrm{mg} / \mathrm{dL}$ (132 mol/L). His EKG was significant for a narrow complex, sinus bradycardia with a rate of 49 , with premature ventricular contractions, normal intervals, and no acute ST or T wave changes were noted. A chest radiograph was normal.

He was resuscitated in the ED with $2 \mathrm{~L}$ of intravenous (IV) normal saline, which improved his systolic blood pressure to 80 $\mathrm{mmHg}$, and aggressive rehydration was continued. He was given $0.5 \mathrm{mg}$ atropine, resulting in an immediate improvement in his $\mathrm{HR}$, which increased from 52 to $93 \mathrm{bpm}$ over 3 minutes, and his BP improved from $88 / 56$ to $132 / 82$ over 8 minutes. Two 4 -mg IV doses of ondansatron and one 12.5-mg IV dose of promethazine were given for vomiting, but did not control his emesis. The Oregon Poison Center was contacted and helped identify Zigadenus as a species likely to be causing his symptoms. The patient subsequently positively identified Zigadenus as the offending plant from photographs obtained via several Internet websites.

The patient was admitted to the ICU with a stable BP and HR, normal mentation, and continued emesis. Three hours after admission, his BP dropped to the 70s/30s with a pulse in the 60s, which was unresponsive to an IV fluid bolus. He was placed on a dopamine drip at $5 \mu \mathrm{g} / \mathrm{kg} / \mathrm{min}$, with return of his BP to 110-130/60s and HR from the 60-70s to a normal range for the rest of the night. Refractory vomiting continued on admission to the ICU, but tapered overnight, and he was asymptomatic the next morning. His dopamine drip was rapidly weaned without event. His BP and pulse remained stable during the next 48 hours in the hospital. He was given a total of $9 \mathrm{~L}$ of IV normal saline. His creatinine normalized to $0.9 \mathrm{mg} / \mathrm{dL}$ ( $79 \mathrm{~mol} / \mathrm{L})$, and he was discharged 48 hours after admission. At discharge he was in his normal state of health and was tolerating a regular diet. He had no lasting effects at 8-month follow-up.

\section{DISCUSSION}

Zigadenus is a perennial herb in the lily family, of which 15 species grow throughout the United States $[1,3]$. The various $Z i-$ gadenus species are also known by several common names, including "death camas" and "foothill camas," among others [2-4]. Reports by early White settlers and Native Americans suggest that the bulbs of the sego lilly (Calochortus nuttallii), camas (genus Camassia), and "wild onions" (Allium mactoptalum) were collected for culinary purposes, and are very similar in appearance to the Zigadenus (Figure 1) [1,5,6]. All have deep V-shaped, onion-like leaves, spikes of yellow flowers from April through June, white bulbs, and grow in similar habitats (Figures 2 and 3) [4,5]. The similar appearance of these edible plants to Zigadenus has led to sev-

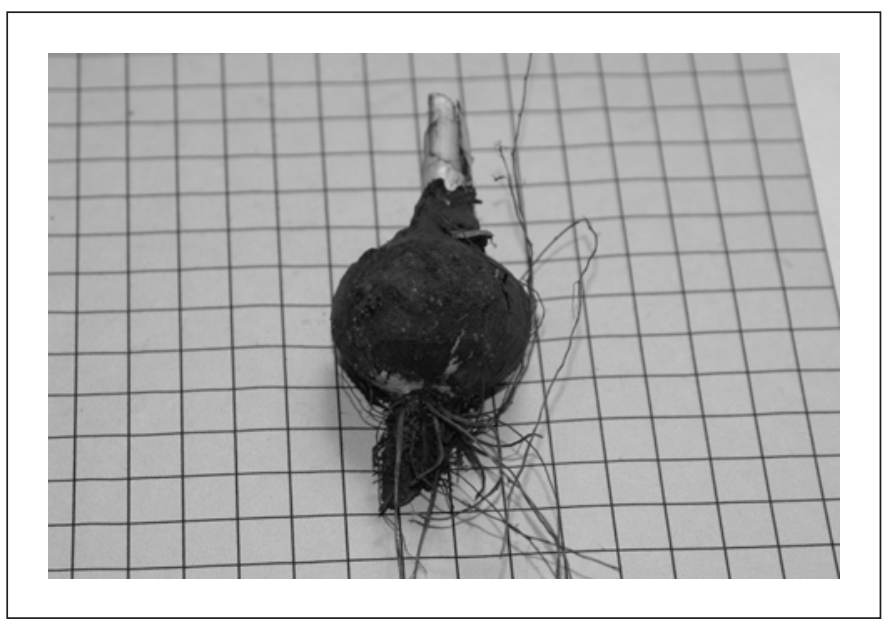

Figure 1: Zigadenus bulb. Photo courtesy of Mary Sue Ittner.

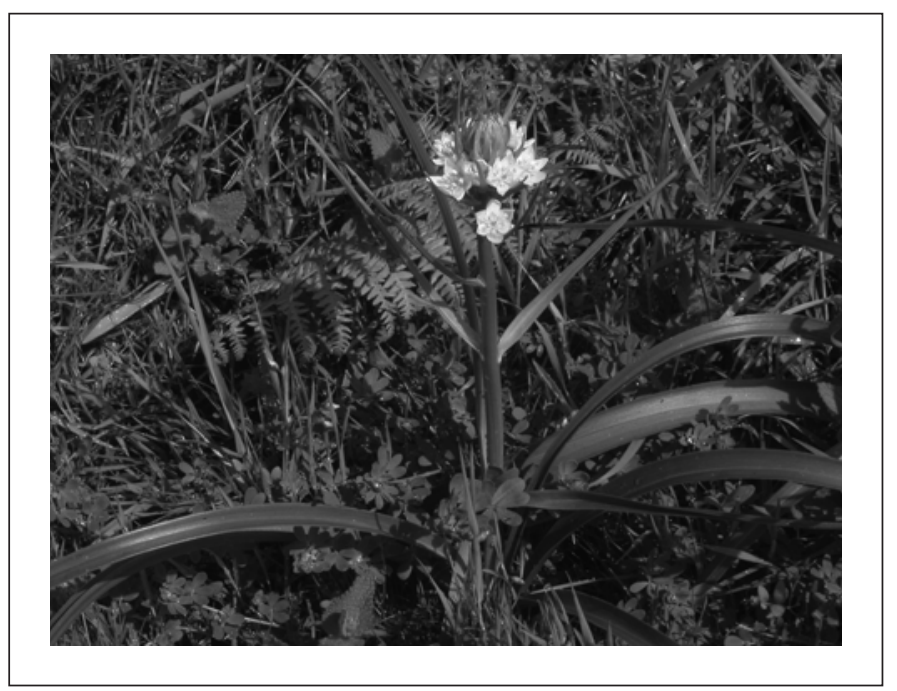

Figure 2: Zigadenus plant. Photo courtesy of Mary Sue Ittner.

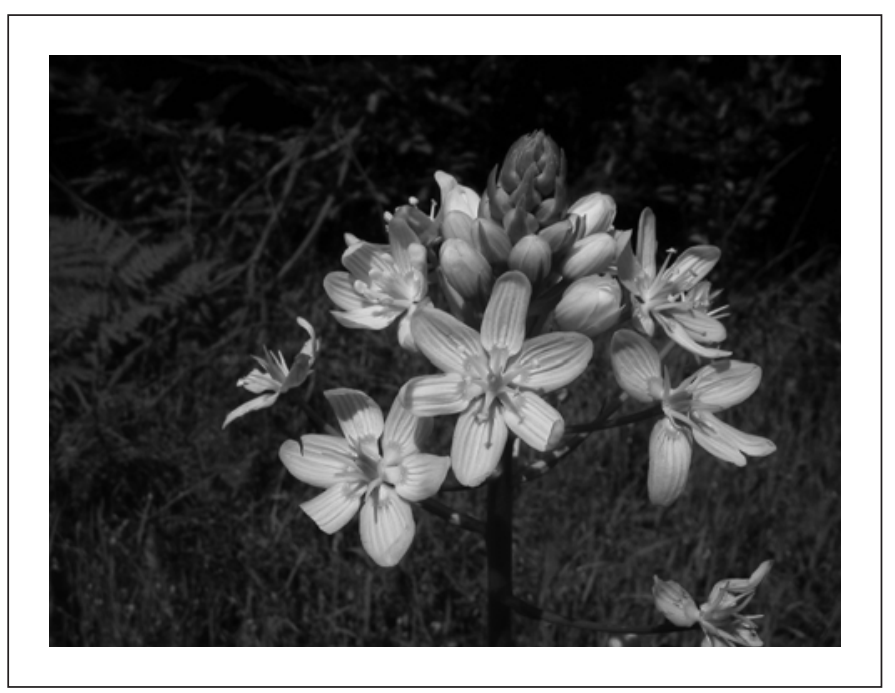

Figure 3: Zigadenus flower. Photo courtesy of Mary Sue Ittner. 
eral episodes of inadvertent poisoning secondary to mistaken identification and ingestion [1,5-7].

There have been several tertiary amines isolated from $\mathrm{Zi}$ gadenus. The two best characterized are veratroyl zygadenine and vanilloyl zygadenine, similar to veratridine alkaloids of the Veratrum species (false hellbore) [8,9]. The effects of these two alkaloids are similar to that of veratridine on muscle, circulatory reflexes, and respiration [8]. Veratridine binds to the alpha subunit of the sodium channel, prolonging sodium channel activation, initially increasing and then decreasing excitability of the neurons, subsequently causing cardiac and neurotoxicity $[10,11]$. The alkaloids cause decreased blood pressure and heart rate that is prevented by "interruption of the conduction" of the vagus nerve [9]. Others have suggested that the degree of hypotension is determined by the quantity of toxin ingested rather than a consequence of the bradycardia [2]. Our case suggests that the former is a more likely etiology of the hypotension, as once the bradycardia was treated with the vagolyticatropine-the hypotension resolved very quickly. The alkaloids are also strong gastric irritants that produce profuse nausea and vomiting [5]. Our patient's symptoms of diaphoresis and salivation are most likely not related to the sodium channel activation, but more likely symptoms from his hypotension and severe vomiting. Poisoning is reported with ingestion of both the root and leaves of the plant as well as in both cooked and raw Zigadenus [1,5,6]. As Zigadenus has been reported to cause a greater number of animal deaths than any other poisonous plant species in certain areas, there is a significant body of animal literature; however, a paucity of scattered reports exists in human literature [3].

The earliest reports of Zigadenus are anecdotes from the Lewis and Clark expedition [6,7]. There is a report from 1930 during the building of the Santa Fe Railroad of Mexican nationals working on the line mistaking Zigadenus for edible bulbs native to Mexico. Several of the workers became severely ill and died before medical care could be obtained [7]. This is the only reported case in which death ensued.

A pediatric case series from the 1950s reported a 2-year-old white male who ate the blossoms of a Zigadenus venosus plant. Soon after ingestion he began vomiting, and then became "comatose" [5]. His BP on arrival was $82 / 0 \mathrm{~mm} / \mathrm{Hg}$, pulse 88 . His respirations were slow and irregular and pupils dilated. He was treated with fluids, caffeine sodium-benzoate, apomorphine, and nikethamide, as was customary in the 1950s. His symptoms resolved within 24 hours, with the exception of ongoing diarrhea. A second child ate roasted Zigadenus bulbs. Within 1 hour, he began vomiting and "staggering." He was brought to the ED with a BP of 52/30 mm/Hg and pulse of 62 . He responded to noise, pupils were dilated but reactive, and he had no abnormal muscular tone or abnormal neurological reflexes. He was treated with nikethamide for coma. Three hours after presentation, his mental status returned to normal and he, too, became asymptomatic except for residual diarrhea (5).

In 1979, the Intermountain Poison Center in Utah reported
3 cases of Zigadenus poisoning [2]. A 4-year-old male ate one bulb, and began to have nausea and vomiting 2 hours after ingestion. He was given activated charcoal in the ED. During his hospitalization, he became bradycardic to $66 \mathrm{bpm}$, but was never hypotensive. Vomiting continued for 5 hours. He was asymptomatic the next morning. A 16-year-old male ate 1 bulb, spitting out half because of its bitter taste. Forty-five minutes after the ingestion he began vomiting and was brought to the ED 3 hours after ingestion. He was bradycardic to $52 \mathrm{bpm}$ but never hypotensive. No therapy was administered. He was asymptomatic at 4 hours and was discharged to home. On recheck in the morning he was well. The third case is of a 25 -year-old male who ate 2 "wild onion" bulbs. He developed vomiting in 1 hour, and was seen in the ED. He was treated with IV fluids. His gastrointestinal symptoms resolved in 4 hours. He was given 3 doses of atropine with an unquantified improvement in heart rate and partial improvement in blood pressure. He was discharged 28 hours postingestion without complaints. Two more cases were reported from the same system, in which bulbs were made into soup: one patient required cardiovascular support and both patients survived [7].

Heilpern reports a 50-year-old Navajo male who was seen in the ED after ingesting half of a Zigadenus paniculatus plant [1]. He began to vomit 1 hour after eating the bulb and presented to the ED also complaining of paresthesias running down both arms, and a "staggering gait." His BP was 83/50 mmHg, and his HR was 48-55 bpm. His exam was notable only for transient abdominal wall fasciculations and ataxic gait on neurological exam. CBC, chemistry panel, urinalysis, urine toxicology, blood cultures, blood ethanol, and head CT were all unremarkable. He was treated with atropine, which raised his HR to $90 \mathrm{bpm}$ and BP to 140/80 $\mathrm{mmHg}$. One hour later, his systolic BP dropped to the 90s and HR returned to the 50s. He was admitted to the ICU and treated with IV fluids. The next day his vomiting and ataxia had resolved. At 2-week follow-up, he was asymptomatic.

A 2003 case series described 8 individuals with Zigadenus ingestion, 6 seeking medical attention, 3 of whom required admission for supportive care [4]. Few individual case details were published. Patients complained of nausea, vomiting, and abdominal pain. Three had hypotension (systolic BP of 81-94 mm/Hg) and bradycardia (46-56 bpm). One had hematemesis. No deaths were reported. No other outcome or treatment data were reported.

The case we present is consistent with the clinical course noted in the literature for Zigadenus poisoning. No remnants of the plant were available for identification and there are no commercially available tests to our knowledge for identification of the toxic amines in blood or body fluids. The identification is limited by the retrospective nature of his visual identification, but given the consistency of the patient's clinical presentation with available literature and his visual identification of the plant, we feel confident that this was a Zigadenus ingestion. Ingestion of Zigadenus is characteristically followed within 1-2 
hours by vomiting, occasional diarrhea, hypotension, and bradycardia. There are occasional reports of ataxia and altered sensorium after ingestion, which was not observed in this case, but could be induced by the prolonged sodium channel activation on nervous tissue. Children seem to have significant alterations in mental status that do not appear to be as prominent in adult ingestions.

There is no true antidote for Zigadenus poisoning. Atropine has been used in several cases of Zigadenus poisoning. In sheep, "death camas tablet" a combination of atropine and picrotoxin has been used with good effect and is commercially available [3]. Most human literature states that atropine is an effective treatment of the bradycardia, but some have reported that it does not resolve the concomitant hypotension [2]. This differs significantly from our case, in which a single dose of $0.5 \mathrm{mg}$ atropine resulted in improvement in both bradycardia and hypotension for 1-2 hours. We feel that a trial of atropine, and possibly multiple doses, is reasonable, as it can quickly and completely stabilize a poisoned patient's vital signs. It has been proposed that vasopressor agents such as dopamine would be effective in treating both the bradycardia and hypotension associated with Zigadenus poisoning, however, their use has not been reported prior to our case $[1,2]$. We achieved significant improvement in BP and pulse rate with inotropic support via dopamine during our patient's second drop in BP and HR (1-2 hours after the atropine). After treatment, our patient had a stable BP over the course of the evening with resolution of symptoms by the next morning, which is consistent with the other Zigadenus ingestions that have been reported. In general, patients seem to be hemodynamically stable within several hours of instituting supportive measures, and symptoms (except occasional diarrhea) resolve within 24 hours. Other recommended treatments have included induced emesis and lavage [2]. We feel that these treatments are unnecessary, as by the nature of the involved toxins, these patients are already vomiting profusely. We also feel that the recommendation for charcoal is misplaced, as uniformly these patients have improved with supportive care and in a vomiting patient, the risk of charcoal aspiration outweighs the possible benefits of charcoal administration to a patient whose gastrointestinal system has already had significant purging.

\section{CONCLUSIONS}

Zigadenus is found throughout the United States, and its onionlike roots can be mistaken for an edible plant. Ingestion cases typically present with vomiting, hypotension, and bradycardia. The hemodynamic instability responds well to atropine for 1-2 hours. Dopamine infusion is effective in stabilization of both HR and BP. With supportive care, poisoned individuals become relatively asymptomatic within 24 hours of their ingestion. Patients do not have any known long-term sequelae after ingestion.

\section{REFERENCES}

1. Heilpern K. Zigadenus poisoning. Ann Emerg Med. 1995;25(2):259-262.

2. Spoerke D, Spoerke S. Three cases of Zigadenus (death camus) poisoning. Vet Hum Toxicol. 1979;21(5):346-347.

3. Kingsbury J. Poisonous Plants of the United States and Canada. Englewood Cliffs, NJ: Prentice-Hall, Inc.; 1974:461-466.

4. Paterson M, Rasmussen G. Intoxication with foothill camas (Zigadenus paniculatus). J Toxicol/Clin Toxicol. 2003;41(1):63-65.

5. Cameron K. Death camas poisoning. Northwest Med. 1952;51:682-683.

6. Ambrose S. Undaunted Courage, Meriwether Lewis, Thomas Jefferson, and the Opening of the American West. New York: Simon and Schuster; 1996:294-296.

7. Wagstaff D, Case A. Human poisoning by Zigadenus. J Toxicol/Clin Toxicol. 1987;25(4):361-367.

8. Krayer O, Rogers B, Kupchan S, et al. Pharmacologic and chemical relation between the veratrum alkaloids and the zygadenus alkaloids. Fed Proc. 1952;11:364.

9. Yaffe S, Kupchan S. Veratrine-like properties of the alkaloidal fractions from Zygadenus venosus. Fed Proc. 1950;9:326.

10. Ulbricht W. Effects of veratridine on sodium currents and fluxes. Rev Physiol Bioch Pharmacol. 1998;133:1-54.

11. Palmer M, Hetz J. Plants. In: Flomenbaum N, Goldfrank L, Hoffman R, Howland M, Lewin N, Nelson L, eds. Goldfrank's Toxicologic Emergencies. 8th ed. New York: McGraw-Hill; 2006:1577-1602. 